\title{
Conservative Management of Placenta Previa-Accreta in a First Trimester Missed Abortion.
}

\author{
Nicolette P. Holliday, MD ${ }^{1}$ \\ 1. Department of Obstetrics \& Gynecology, University of South Alabama, Mobile, Alabama
}

\section{Abstract}

The incidence of placenta accreta has been increasing along with the incidence of caesarean sections. There have only been a few case reports of placenta accreta diagnosed in the first trimester, and none in association with a missed abortion in a woman without risk factors. At a routine prenatal visit, a 33 year old G2P0101 at $12+6$ weeks had an ultrasound demonstrating a fetus with a crown-rump length of $8+0$ weeks, no fetal heart tones, a placenta previa, and a morbidly adherent placenta. The patient requested conservative management to help preserve her fertility. Imaging demonstrated an anterior placenta previa with extension of the placenta past the inner endometrium into the superficial myometrium wall and the myometrium adjacent to the superior surface of the bladder. Consultation with Maternal Fetal Medicine (MFM) at another institution similarly demonstrated a suspicion of vascular invasion of the uterine wall with no increased vascularity extending to the maternal bladder using color flow Doppler. The opinion from this second MFM team recommended expectant management with serial beta-hCG, ultrasounds, and serial physician visits as well. Her beta-hCG levels declined serially from 55262 to $4874 \mathrm{mIU} / \mathrm{mL}$ over eight weeks. Her serial ultrasounds showed involution of the placenta and reasborption of the fetus during that time. After nine weeks of conservative management, the patient underwent an uncomplicated suction dilation and curettage. Postoperatively, the patient did well and did not have any complications. A first trimester missed abortion with a placenta previa and accreta can be managed conservatively in the attempt to preserve future fertility.

\section{Introduction}

Placenta accreta was first described in the literature in 1937 by Irving and Hertig. ${ }^{1} \quad$ It results from abnormal invasion of trophoblastic tissue into the myometrium through a defective basal decidua. ${ }^{2}$ This condition is more likely present in the lower uterine ${ }^{1}$ segment where Nitabuch's layer is deficient or absent. ${ }^{2,3}$ Risk factors for this condition include placenta previa, multiparity, advanced maternal age, cesarean section, myomectorhy, previous corneal resection, submucosal fibroids, previous dilation and curettage (D\&C), Asherman's syndrome, short cesarean-to-conception interval, intrauterine infection, history of miscarriage or abortion, history of postpartum hemorrhage with 
retained placenta, multiple pregnancy, female fetus, maldevelopment of the uterus, corneal implantation, hypoplasia of the endometrium, endometrial ablation, pelvic radiation, smoking, resection of a uterine septum, and hypertensive disorders. ${ }^{1-9}$ Rarely, a patient will have no risk factors with this condition. ${ }^{1,10}$

The incidence of placenta accreta has increased over the decades along with the increasing incidence of cesarean section. ${ }^{9}$ Before the 1950s, the incidence of placenta accreta was less than 1 in 30000 deliveries, but in 1980, the rate had increased to 1 in 2500 deliveries. ${ }^{11}$

\section{Case}

A 33 year old G2P0101 with an intrauterine pregnancy at $12+6$ weeks by last menstrual period consistent with a $7+5$ week ultrasound had a repeat ultrasound for viability. Ultrasound showed a crown-rump length of $8+0$ and no fetal heart tones. The anterior placenta previa was thickened with multiple lakes. The lacunae were grade 3 by Finberg and Williams score. ${ }^{12}$ There was an ill defined placental uterine interface as well.

The patient had no risk factors for a placenta accreta. Her first delivery was an induced vaginal delivery at 33 weeks for pre-eclampsia. She denied any history of dilation and curettage, manual placenta removal, or uterine surgery/instrumentation. Her only significant history was for hypothyroidism and a laparoscopic cholecystectomy.

Our Maternal Fetal Medicine specialist recommended conservative management with magnetic resonance imaging (MRI), serial beta-hCG, serial ultrasounds, frequent clinic visits, and strict precautions. After counseling the patient about the uniqueness and gravity of her situation, she elected for the conservative management with expectant management over a scheduled suction D\&C.

Her MRI demonstrated an anterior placenta previa with extension of the placenta past the inner endometrium into the superficial myometrium wall and the myometrium adjacent to the superior surface of the bladder. There was a well-defined tissue plane seen between the bladder wall and the myometrium without evidence of breakthrough. Her beta-hCG levels declined serially from 55262 to $4874 \mathrm{mIU} / \mathrm{mL}$ over eight weeks. Her serial ultrasounds showed involution of the placenta and reasborption of the fetus during that time.

She had a second opinion at another academic institution where their ultrasound also showed the absence of a sonolucent subplacental layer. Using Color flow Doppler, there was suspicion of vascular invasion of the uterine wall with no increased vascularity extending to the maternal bladder. The Maternal Fetal Medicine physicians at that institution also recommended expectant management with weekly beta hCG and then a suction D\&C if there was bleeding or infection.

After nearly nine weeks of conservative management with only minimal vaginal spotting and cramping, the patient requested a D\&C due to mental exhaustion.

One week later, after consent for a D\&C with possible hysterectomy, she underwent a suction D\&C without complication. Pathology revealed chorionic villi, deciduas with acute inflammation, gestational endometrium, and no fetal parts identified. Postoperatively, she did well and had no problems with bleeding.

\section{Discussion}

Diagnosis of placenta accreta can be made by microscopic examination ${ }^{13}$ and can be detected by imaging procedures, with sonography being the most common. ${ }^{14}$ Ultrasound has a sensitivity of $77-87 \%$, specificity of 96-98\%, positive predictive value (PPV) of $65-93 \%$, and negative predictive value (NPV) of $98 \% .^{15}$ Sonographic criteria includes the absence of a normal hypodense retroplacental-myometric zone, a reduced or absent surface between uterine serosa and urinary bladder, the presence of focal exophytic tissue, and lacunae within the placenta. ${ }^{15,16}$ Visualization of the lacunae is the most reliable predictive sign and has a sensitivity of 79-93\% and PPV of 92$93 \%$. $^{7,17,18}$ Thinning of the myometrium less than 1 mm suggests abnormal placentation with a sensitivity of $93 \%$, specificity of $79 \%$, and PPV of $73 \% .^{7}$ Transvaginal Doppler ultrasound may highlight areas 
of increased vascularity from dilated blood vessels crossing the placenta and myometrium. ${ }^{16}$ Doppler flow ultrasonography has a sensitivity of $90.74 \%$ and a specificity of $87.68 \% .{ }^{19}$ Specific to the first trimester, findings suspicious for accreta include abnormally low implantation of the gestational sac and an irregular appearance of the developing placental-myometrial interface. ${ }^{9}$

MRI can be used as a supplementary diagnostic procedure especially if the placenta is posterior. ${ }^{14}$ MRI has a sensitivity of $80-93 \%$ and a specificity of $65-$ $85 \%$ for diagnosing an accreta. ${ }^{20}$ Failure to demonstrate adherence of the clinically suspected placenta accreta to the myometrium cannot be used to exclude the diagnosis of placenta accreta. ${ }^{21}$

Compared to when the diagnosis of a placenta accreta is made antenatally, there is increased risk of peripartum morbidity and mortality for both the mother and neonate when the diagnosis is made at time of delivery. ${ }^{9}$ Complications of placenta accreta can include uterine rupture and catastrophic hemorrhage requiring peripartum hysterectomy. ${ }^{3,13}$ The average blood loss at delivery of a patient with placenta accreta is 3000 $5000 \mathrm{~mL}{ }^{22}$ The rate of peripartum hysterectomy is 1.0 to 1.4 per thousand deliveries, and placenta accreta is reported as the leading or second most common indication for that peripartum hysterectomy. ${ }^{6}$

Historically, placenta accreta has been managed with laparotomy and hysterectomy. ${ }^{2,3,23}$ An article from 1950 reported zero mortality with hysterectomy but a $70 \%$ mortality with manual attempts at removal. ${ }^{3}$ An article from 1972 reports maternal mortality from hysterectomy was $5.8-6.6 \%$ and $12.5-28.3 \%$ with attempts at conservative management. ${ }^{4}$ More recently, management for third trimester placenta accreta has included suture of bleeding site, curettage, uterine artery ligation, hypogastric artery ligation, leaving the placenta in situ with and without methotrexate. ${ }^{1,4,14,16}$

Our offering of conservative management of a placenta previa and accreta in the setting of a first trimester missed abortion has not been documented in the literature before. One systematic review on the topic documented conservative management including uterine artery embolization, transcatheter arterial chemoembolization with dactinomycin, and laparoscopic hysterotomy with placental tissue removal. ${ }^{24}$ Our case offers expectant management as a conservative approach which resulted in a non-complicated Suction D\&C. There are no evidence based recommendations for management of patients seeking first- and second-trimester abortions with a diagnosis of placenta accreta. ${ }^{25}$ Previous studies investigating placenta accreta in the first two trimesters have evaluated the outcomes of hysteroscopic resection, ${ }^{26}$ dilation and evaluation, ${ }^{16}$ uterine artery embolization, ${ }^{18,25}$ chemotherapy with methotrexate, mifepristone, or both. ${ }^{8}$

We contend that in a first trimester missed abortion with a placenta previa and accreta, conservative management may be offered to those patients desiring future fertility who want to minimize risks of complications.

\section{References}

1. Read JA, Cotton DB, Miller FC. Placenta accreta: changing clinical aspects and outcome. Obstetrics \& Gynecology. 1980;56(1):31-34.

2. WACHSMAN DV, MOORE GL. Placenta previa and accreta; report of two cases. Obstetrics \& Gynecology. 1956;7(4):399-405.

3. MANNING RE, PAVEY CW. Placenta accreta: report of two cases, one with spontaneous uterine rupture. Obstetrics \& Gynecology. 1959;14:793-795.

4. Miller DA, Chollet JA, Goodwin TM. Clinical risk factors for placenta previa-placenta accreta. American Journal of Obstetrics and Gynecology. 1997;177(1):210-214. doi:10.1016/s00029378(97)70463-0

5. Hung TH, Shau WY, Hsieh CC, Chiu TH, Hsu JJ, Hsieh TT. Risk factors for placenta accreta. Obstetrics \& Gynecology. 1999;93(4):545-550. doi:10.1016/ s0029-7844(98)00460-8

6. Usta IM, Hobeika EM, Musa AA, Gabriel GE, Nassar AH. Placenta previa-accreta: risk factors and complications. American Journal of Obstetrics and Gynecology. 2005;193(3 Pt 2):1045-1049. doi:10.1016/j. ajog.2005.06.037 
7. Palacios-Jaraquemada JM. Diagnosis and management of placenta accreta. Best Practice \& Research: Clinical Obstetrics \& Gynaecology. 2008;22(6):11331148. doi:10.1016/j.bpobgyn.2008.08.003

8. Li P, Zheng Q, Xiong B, Cai H. Sonographic features of placenta accreta after first-trimester abortion. Journal of Ultrasound Medicine. 2013;32(8):15091514. doi:10.7863/ultra.32.8.1509

9. Ballas J, Pretorius D, Hull AD, Resnik R, Ramos GA. Identifying sonographic markers for placenta accreta in the first trimester. Journal of Ultrasound Medicine. 2012;31(11):1835-1841 . doi:10.7863/ jum.2012.31.11.1835

10. Wong HS, Zuccollo J, Tait J, Pringle KC. Placenta accreta in the first trimester of pregnancy: sonographic findings. Journal of Clinical Ultrasound. 2009;37(2):100-103. doi:10.1002/jcu.20487

11. Wu S, Kocherginsky M, Hibbard JU. Abnormal placentation: twenty-year analysis. American Journal of Obstetrics and Gynecology. 2005;192(5):14581461 . doi:10.1016/j.ajog.2004.12.074

12. Finberg HJ, Williams JW. Placenta accreta: prospective sonographic diagnosis in patients with placenta previa and prior cesarean section. Journal of $U l$ trasound Medicine. 1992;11(7):333-343. doi:10.7863/ jum.1992.11.7.333

13. SCHRAM M, ASKARI M. Spontaneous Rupture of Uterus caused by placenta accreta at 17 weeks' gestation. Report of a case. Obstetrics \& Gynecology. 1965;25:624-628.

14. Hopker M, Fleckenstein G, Heyl W, Sattler B, Emons G. Placenta percreta in week 10 of pregnancy with consecutive hysterectomy: Case report. Human Reproduction. 2002;17(3):817-820. doi:10.1093/hum$\mathrm{rep} / 17.3 .817$

15. Committee on Obstetric Practice. Committee opinion no. 529: placenta accreta. Obstetrics \& Gynecology. 2012;120(1):207-211. doi:10.1097/ AOG.0b013e318262e340
16. Chen YJ, Wang PH, Liu WM, Lai CR, Shu LP, Hung JH. Placenta accreta diagnosed at 9 weeks' gestation. Ultrasound in Obstetrics \& Gynecology. 2002;19(6):620-622. doi:10.1046/j.14690705.2002.00707.x

17. Comstock CH, Love JJ Jr, Bronsteen RA, et al. Sonographic detection of placenta accreta in the second and third trimesters of pregnancy. American Journal of Obstetrics and Gynecology. 2004;190(4):11351140. doi:10.1016/j.ajog.2003.11.024

18. Yang JI, Kim HY, Kim HS, Ryu HS. Diagnosis in the first trimester of placenta accreta with previous Cesarean section. Ultrasound in Obstetrics \& Gynecology. 2009;34(1):116-118. doi:10.1002/uog.6407

19. D'Antonio F, Iacovella C, Bhide A. Prenatal identification of invasive placentation using ultrasound: systematic review and meta-analysis. Ultrasound in Obstetrics \& Gynecology. 2013;42(5):509-517. doi:10.1002/uog.13194

20. Mansour S, Elkhyat W. Placenta previa - accreta: Do we need MR imaging? The Egyptian Journal of Radiology and Nuclear Medicine. 2011;42(3-4):433442. doi:10.1016/j.ejrnm.2011.09.002

21. Gielchinsky Y, Mankuta D, Rojansky N, et al. Perinatal outcome of pregnancies complicated by placenta accreta. Obstetrics \& Gynecology. 2004 Sep;104(3):527-530. DOI: 10.1097/01. aog.0000136084.92846.95.

22. Hudon L, Belfort MA, Broome DR. Diagnosis and management of placenta percreta: a review. Obstetrical \& Gynecological Survey. 1998;53(8):509517. doi:10.1097/00006254-199808000-00024

23. Rashbaum WK, Gates EJ, Jones J, Goldman B, Morris A, Lyman WD. Placenta accreta encountered during dilation and evacuation in the second trimester. Obstetrics \& Gynecology. 1995;85(5 Pt 1):701-703. doi:10.1016/0029-7844(95)00050-2

24. Wang YL, Weng SS, Huang WC. First-trimester abortion complicated with placenta accreta: A systematic review. Taiwanese Journal of Obstetrics \& Gynecology. 2019;58(1):10-14. doi:10.1016/j. tjog.2018.11.032 
25. Tocce K, Thomas VW, Teal S. Scheduled hysterectomy for second-trimester abortion in a patient with placenta accreta. Obstetrics \& Gynecology. 2009;113(2 Pt 2):568-570. doi:10.1097/AOG. Ob013e318194258c

26. Confino, Edmund MD; Robins, Jared C. MD; Williams, Amy E. MD Surgical Management of Placenta Accreta After Early Pregnancy Loss, Obstetrics \& Gynecology: May 2014 - Volume 123 - Issue - p 188S doi: 10.1097/01.AOG.0000447214.45206.1e 